\title{
С.В. Санникова
}

Челябинский государственный педагогический университет,
Челябинск, Россия

\section{МЕЖКУЛЬТУРНЫЙ КОМПОНЕНТ ПРОФЕССИОНАЛЬНО-ОРИЕНТИРОВАННОГО ОБУЧЕНИЯ ГУМАНИТАРИЕВ}

\begin{abstract}
В статье рассматриваются вопросы соотношения языка и культуры, межкультурной коммуникации, необходимости формирования профессионально-ориентированной коммуникативной компетенции, а также актуальные проблемы языкознания XXI века - проблемы взаимодействия мировых культур в области языка. В современных условиях процесс обучения иностранным языкам складывается в рамках социокультурной модели обучения, которая рассматривается как основа осуществления межкультурной коммуникации, общение языковых личностей, принадлежащих к различным лингвокультурным сообществам. Говорящий на иностранном языке должен не только правильно формулировать мысли, но и соблюдать культурные нормы, принятые у носителей изучаемого языка. Осваивая язык, обучающийся должен проникнуть и в иную систему ценностей и жизненных ориентиров и интегрировать ее в собственную картину мира. Целью обучения иностранным языкам становится формирование языковой личности, способной осуществлять эффеективное общение с представителями других культур. Автор описывает факторы, обусловившие обращение к новой парадигме в лингводидактике, говорит о ценностной значимости формирования навыков профессионально-ориентированного общения. Вопросы межкультурной коммуникации рассматриваются в историческом аспекте и в рамках профессиональноориентированного обучения студентов неязыковых специальностей в вузе. Раскрываются факторы, обеспечивающие эффективное обучение профессионально-ориентированному иностранному языку.

Ключевые слова: язык, культура, межкультурная коммуникация, профессиональноориентированное обучение, неязыковые факультеты, Государственный образовательный стандарт, иноязычное общение.
\end{abstract}

\author{
S.V. Sannikova \\ Chelyabinsk State Pedagogical University, \\ Chelyabinsk, Russia
}

\section{INTERCULTURAL COMPONENT IN TEACHING LANGUAGE FOR SPECIFIC PURPOSES TO HUMANITARIANS}

The article deals with the language and culture relations, intercultural communication, the necessity of profession-oriented communicative competence formation as well as with topical issues of Linguistics of the XXI century problems of interaction between the world's cultures in the field of language. In modern conditions, the process of teaching a foreign language develops in the framework of the socio-cultural model of teaching, which is regarded as the basis for intercultural communication, communication between language personalities belonging to different linguisticcultural communities. Speaking a foreign language, one must not only correctly formulate thoughts, but also respect cultural norms of natives. Students mastering a language must understand a different system of values and life landmarks and integrate this system into their own picture of the world. The purpose of teaching a foreign language is then to form linguistic personality capable to communicate effectively with representatives of other cultures. The author describes the factors that led to a new treatment paradigm in linguistics, talks about the importance of values in formation of skills of profession-oriented communication. The aspects of intercultural communication are discussed in historical perspective and within the professionally oriented training of students of non-linguistic specialties at high school. Factors of effective profession-oriented teaching a foreign language are revealed.

Keywords: language, culture, intercultural communication, teaching language for specific purposes, nonlinguistic faculties, State Educational Standard, foreign language communication. 
Вопросы соотношения языка и культуры, межкультурной коммуникации, необходимости формирования профессионально-ориентированной коммуникативной компетенции обсуждаются в неслыханных масштабах не первое десятилетие и не только на уровне преподавания иностранных языков, но и на правительственном и даже военном уровнях. Совершенно очевидно, что частотность и повторяемость материалов связаны с объективными причинами глобализацией, политическими катаклизмами и этническими конфликтами, стремительным техническим прогрессом, благодаря которому человечество обрело невиданные способы общения. На рубеже второго и третьего тысячелетий стало очевидным, что человечество развивается по пути расширения взаимосвязи и взаимозависимости различных стран, народов и культур [1]. Важную роль в сосуществовании людей в общем жизненном пространстве играет язык, с помощью которого становится возможным достижение взаимопонимания и взаимодействия между представителями различных лингвосообществ [2]. Следовательно, неоспоримым фактом является способность эффективно участвовать в межкультурной коммуникации.

Сегодня различным формам коммуникации и общения обучают во многих российских вузах. Основным требованием Государственного образовательного стандарта высшего профессионального образования по иностранным языкам для неязыковых специальностей является практическое владение студентами иноязычной речью как в повседневном, так и в профессиональном общении. Очевидно, что овладение знаниями и навыками межкультурной коммуникации продиктовано практическими потребностями реальной жизни.

Датой рождения межкультурной коммуникации как академической дисциплины следует считать 1954 год, когда вышла в свет книга Э. Холла и Д. Трагера «Culture as Communication». Теоретическое и прикладное научное направление «Межкультурная коммуникация» активно разрабатывалось во многих странах: Англии, Германии, Испании и было востребовано обществом. В России, точнее в российском образовательном пространстве, словосочетание «межкультурная коммуникация» стало широко употребительным лишь в конце 90-х годов, что было связано с коренными изменениями в отношении к предмету «Иностранный язык» по вполне определенным социально-историческим причинам [3]. Изменение социокультурного контекста, причастность России к процессам глобализации в современном мире, результатом которой явилась политическая, экономическая и культурная интеграция, повлекли за собой радикальные изменения в методическом и содержательном аспектах преподавания иностранных языков. Основными перспективными задачами в обучении иностранному языку стали максимальное развитие коммуникативных способностей и углубление роли социокультурного компонента в развитии данных способностей. Так, в 1997 году классификатором специальностей Министерства общего и среднего образования Российской Федерации было официально 
закреплено новое название специальности «Иностранные языки» - «Лингвистика и межкультурная коммуникация», а содержание обучения иностранным языкам наполнилось социокультурными маркерами. Это стало отправной точкой для коллектива факультета иностранных языков и регионоведения МГУ имени М.В. Ломоносова в работе над учебными программами, обеспечивающими наполнение специальности «Межкультурная коммуникация». Сегодня различным формам коммуникации и общения обучают во многих российских вузах не только потому, что для целого ряда специальностей изучение норм, правил и стилей коммуникации является обязательным в соответствии с Государственным образовательным стандартом, а прежде всего потому, что овладение знаниями и навыками коммуникации диктуется практическими потребностями реальной жизни. А современные реалии свидетельствуют о том, что страны и народы активно сотрудничают и взаимодействуют друг с другом во всех сферах жизни, будь то политика, экономика, культура, на разных уровнях, начиная с личного общения, заканчивая международными встречами.

Сотрудничество в международных политических, экономических и профессиональных организациях, участие в международных форумах, конференциях, работа в многонациональных компаниях, обмен опытом в профессиональной сфере, обучение за рубежом - все эти и многие другие факторы подводят к необходимости изучения языка и иноязычной культуры для адекватного межкультурного общения. Изучение иностранного языка начинается в школе и продолжается в университете. «Основная задача преподавания иностранных языков в высшей школе - это обучение языку как средству общения между специалистами разных стран - общения в разных формах: письменной и устной. Традиционно преподавание иностранных языков для неязыковых специальностей сводилось в нашей стране к чтению специальных текстов. Таким образом реализовывалась только одна функция языка и, соответственно, один аспект триединой задачи университетского образования, а именно: функция сообщения, информативная функция, соответственно, образовательная задача профессиональной подготовки студентов - и то весьма в суженном виде, так как из четырех навыков (чтение, говорение, письмо, понимание на слух) развивался только один - пассивный, ориентированный на “узнавание” - чтение» [4, с. 4-5].

Отчасти это можно объяснить тем, что Россия была отгорожена от западных стран «железным занавесом». Преподавание иностранных языков на основании письменных текстов сводило коммуникативные возможности языка лишь к пассивной способности понимать кем-то созданные тексты, но не создавать, не порождать речь, без чего невозможно реальное общение [4].

Именно поэтому на рубеже второго и третьего тысячелетий, когда стало очевидным, что человечество развивается по пути расширения взаимосвязи и взаимозависимости различных стран, народов и их культур, обучение иностран- 
ному языку как средству общения между специалистами разных стран начали понимать не как чисто прикладную и узко специальную задачу обучения. Востребованный специалист высшей школы должен быть широко образованным человеком, имеющим фундаментальную подготовку, специалистом, для которого иностранный язык является и орудием производства, и частью культуры.

Итак, в современных условиях межкультурная коммуникация, иноязычное общение стали неотъемлемым компонентом будущей профессиональной деятельности специалиста. В.М. Постоев наглядно продемонстрировал значительные лингвистические отличия между лексическим и грамматическим материалом общеупотребительного языка и специального подъязыка. Основной характеристикой преподавания иностранного языка на неязыковых специальностях, по мнению ученого, «должна стать отраслевая специфика, совокупность методов и подходов, которые отражают особенности будущей специальности студентов и особенности процесса овладения ею» [5, с. 6]. В связи с этим становится очевидной актуальность профессионально-ориентированного подхода к обучению иностранного языка на неязыковых факультетах вузов, который предусматривает формирование у студентов способности иноязычного общения в конкретных профессиональных, деловых, научных сферах и ситуациях с учетом особенностей профессионального мышления, при организации мотивационно-побудительной и ориентировочно-исследовательской деятельности [6]. Необходимо отметить и тот факт, что Государственный образовательный стандарт высшего профессионального образования требует учета профессиональной специфики при изучении иностранного языка, его нацеленности на реализацию задач будущей профессиональной деятельности выпускников.

Различные аспекты профессионально-ориентированного обучения иностранным языкам на неязыковых факультетах вузов рассматривались в исследованиях А.С. Балахонова, Л.И. Буровой, И.Н. Григоренко, Ю.А. Зусман, С.В. Касилиной, С.О. Китаевой, Э.П. Комаровой, Т.В. Кучмы, Н.Л. Лукошкиной, СА. Проценко, Т.С Серовой и др.

Анализ педагогической теории и практики профессионально-ориентированного обучения иностранному языку студентов неязыковых факультетов вузов позволяет выделить четыре этапа становления данной проблемы.

Первый этап - 50-70 годы ХХ столетия характеризуется появлением профильного обучения иностранному языку в неязыковых вузах. Изучение предмета «Иностранный язык» ограничивалось изучением так называемого «специализированного макроязыка». В центре внимания находились вопросы подбора и выявления лингвистических особенностей текстов и создания специализированных учебных и учебно-методических пособий (И.Г. Веникова, 3.М. Цветкова, Л.И. Чаурская, Л.Ю. Кулиш и др.). Большинство исследователей, принадлежащих к данному этапу, пришли к выводу о том, что для развития навыков чтения литературы по специальности и навыков устной речи не- 
обходимы адаптированные специализированные тексты. По их мнению, новизна содержания специализированных текстов способствовала повышению интереса к изучению иностранного языка и расширению кругозора студентов по их будущей специальности. В этот период дисциплина «Иностранный язык»не является значимой для большинства студентов. Но уже к концу 60-х годов XX века иностранный язык становится средством повышения уровня знаний в рамках своей специальности и формирования профессиональной направленности студента. В своем исследовании Е.В. Рощина рассматривает иностранный язык как средство формирования профессиональной направленности будущего специалиста, отмечая, что при изучении профессионально-ориентированного языкового материала устанавливается двусторонняя связь между стремлением студента приобрести специальные знания и успешностью овладения языком. Мы согласны с автором в ее отношении к иностранному языку как эффективному средству профессиональной и социальной ориентации в неязыковом вузе, которое располагает большим потенциалом формирующих воздействий [7].

Огромный вклад в разработку теории профессионально-ориентированного преподавания иностранного языка на первом этапе внес М.В. Ляховицкий, обосновавший принцип профессиональной направленности учебного материала при обучении иностранному языку в неязыковых вузах [8]. Изучение иностранного языка, по мнению автора, должно быть не самоцелью, а средством достижения цели - повышения уровня образованности, эрудиции в рамках своей узкой специальности. Учет специфики профилирующих специальностей М.В. Ляховицкий предлагал проводить по следующим направлениям:

- работа над специальными текстами;

- изучение специальных тем для развития устной речи;

- изучение словаря-минимума по соответствующей специальности;

- создание преподавателями пособий для активизации грамматического и лексического материала обучающихся.

В 70-х годах XX века в целях получения более прочных профессиональных знаний предлагалось использовать страноведческий комментарий на занятиях по иностранному языку в неязыковых вузах (В.А. Скрозникова, P.М. Боданкина и др.). Авторы отмечали, что краткие комментарии страноведческого или лингвострановедческого характера четко обнаруживают связь практики обучения иностранному языку с содержанием программ других дисциплин и оказывают положительное воздействие на приобретение студентами неязыковых вузов более глубоких профессиональных знаний [9]. По мнению авторов, назрела необходимость в создании профессиональноориентированных пособий, которые содержали бы страноведческий материал. Объективное развитие педагогической науки неизбежно привело к поиску новых, более эффективных методических направлений. В обучении речевой 
деятельности появились тенденции, которые все более признавались плодотворными и перспективными. Одной из них являлась тенденция к усилению коммуникативной направленности учебного процесса.

Второй этап становления проблемы профессионально-ориентированного обучения на неязыковых специальностях вузов приходится на 70-80 годы XX века, когда на неязыковых факультетах вузов проявляется повышенный интерес к дисциплине «Иностранный язык», к проблеме самостоятельной работы студентов по пополнению своих профессиональных знаний средствами иностранного языка (Т.О. Гарбер, А.И. Козырева, Л.И. Корникова, Ф.Л. Лемберская, П.О. Русанова, Л.В. Столбовая и др.). Такой интерес объяснялся тем, что в условиях возрастания объема профессиональных знаний, необходимых будущему специалисту, важно научить его ориентироваться в потоке информации по выбранной специальности. В связи с этим большое внимание уделялось подбору высокоинформативных профессиональных текстов и разработке системы упражнений к ним. Основной целью обучения иностранному языку на данном этапе является обучение чтению литературы с учетом профессиональных потребностей будущего специалиста.

Третий этап становления проблемы профессионально-ориентированного обучения иностранному языку на неязыковых факультетах вузов - 80-90 годы $\mathrm{XX}$ столетия. Данный этап характеризуется постановкой вопроса о повышении роли дисциплины «Иностранный язык» в формировании у обучающихся качеств, определенных квалификационными характеристиками специалистов. Исследователи Т.Ю. Полякова, Е.В. Синявская и другие отмечают, что успешное развитие творческой личности и необходимых для профессии качеств невозможно без учета интересов и потребностей студентов [6]. А это, в свою очередь, должно быть отражено в учебных материалах и построении учебного процесса. Учебники и учебные пособия по иностранному языку того периода, к сожалению, были крайне идеологизированы, содержали мало страноведческого материала и аутентичных текстов. Их содержание не было направлено на развитие у студентов навыков общения в сфере профессиональной деятельности.

Радикальное изменение социальной жизни нашей страны, ее стремительное вхождение в мировое сообщество в 90-е годы XX века изменили коренным образом отношение к иностранному языку как учебной дисциплине. Наступил четвертый этап становления проблемы профессионально-ориентированного обучения иностранному языку на неязыковых специальностях вузов. Основной целью становится обучение иностранному языку как реальному средству общения между специалистами разных стран. Развитие всех языковых навыков (чтение, говорение, письмо и аудирование) приобретает профессионально-ориентированный характер.

Именно изменение социально-экономической и политической ситуации в стране в конце 90-х годов XX века послужило катализатором внедрения 
новых подходов, методов и технологий обучения иностранному языку, способствующих расширению кругозора и повышению профессиональной компетентности будущих специалистов. Одним из методических требований к процессу профессионально-ориентированного обучения становится адекватность процесса обучения реальному процессу коммуникации. Набирает обороты коммуникативный подход, начинается внедрение лингвострановедческого, социокультурного, межкультурного, функционально-понятийного подходов в обучении общению на иностранном языке. Коммуникативное развитие студентов на занятиях иностранного языка осуществляется за счет интеграции и правильной реализации перечисленных подходов, внедрения новых моделей языкового образования.

Логика изучения проблемы становления профессионально-ориентированного обучения иностранному языку на неязыковых специальностях вузов определяет задачу рассмотрения основного понятия «профессионально-ориентированное обучение иностранному языку». Вместе с тем рамки статьи не предполагают глубокого анализа всех дефиниций, отраженных в исследованиях по данному направлению. На наш взгляд, наиболее полное определение, отражающее суть профессионально-ориентированного обучения иностранному языку, дано в учебном пособии П.И. Образцова и О.Ю. Ивановой «Профессионально-ориентированное обучение иностранному языку на неязыковых факультетах вузов»: «Под профессионально-ориентированным понимается обучение, основанное на учете потребностей студентов в изучении иностранного языка, диктуемого особенностями будущей профессии или специальности» [6]. Мы согласны с авторами пособия в том, что развитие личностных качеств будущих специалистов сочетается с овладением профессионально-ориентированным иностранным языком и знанием культуры страны изучаемого языка. Профессионально-ориентированное обучение иностранному языку необходимо осуществлять в его интеграции со специальными дисциплинами будущей профессии с целью получения дополнительных профессиональных знаний и формирования профессионально значимых качеств личности. В этом случае, по мнению П.И. Образцова и О.Ю. Ивановой, «иностранный язык выступает средством повышения профессиональной компетентности и личностно-профессионального развития студентов и является необходимым условием успешной профессиональной деятельности специалиста - выпускника современной высшей школы» [6].

Теоретическое осмысление проблемы подтверждает мысль о том, что профессионально-ориентированное обучение иностранному языку признается приоритетным направлением в обновлении образования на современном этапе. Вместе с тем необходимо признать факт отсутствия специальной подготовки преподавателей иностранного языка для неязыковых факультетов вузов, дефицита учебной литературы для повышения профессиональной компетентности 
преподавателей иностранного языка, работающих на неязыковых специальностях. Как правило, преподаватели иностранного языка, работающие на неязыковых факультетах вуза, занимаются самообразованием, чтобы восполнить данный пробел. Компилируя различные подходы, методы, средства обучения иностранному языку для специальных целей, преподаватели находят ту золотую середину, которая приемлема в данной конкретной профессиональноориентированной среде факультета вуза. Например, одним из путей преодоления трудностей профессионально-ориентированной подготовки студентов неязыковых специальностей может стать взаимодействие различных структурных подразделений вуза, таких как кафедра иностранных языков и узкоспециализированные кафедры, ведущие профильную подготовку [10].

Профессионально-ориентированное обучение иностранным языкам - это прагматическое обучение. В конкретных условиях конкретного неязыкового факультета вуза (исторического, юридического, естественно-технологического и т.д.) это означает, что владение иностранным языком по содержанию и методике обучения должно служить профессиональной (исторической, юридической, технической) подготовке будущего специалиста. Анализ содержания обучения английскому языку только трех факультетов - исторического, юридического, факультета психологии - показал, что учебники/учебные пособия для студентов младших курсов не отражают новые целевые установки. Языковая подготовка студентов не отражает профессионально-ориентированных сценариев и прагматических ситуаций общения. В учебниках либо практически отсутствуют профессионально-актуальные аутентичные тексты, либо в основной представлены адаптированные учебные тексты. В вузах, где созданы кафедры иностранных языков для неязыковых специальностей, а программа языковой подготовки студентов предусматривает аспект обучения языку для специальных целей на материале научной речи (например, географический факультет МГУ им. М.В. Ломоносова), в качестве основного учебного пособия используется аутентичный учебник издательства Longman «Environment today». Однако практика преподавания показала, что данного пособия, которое содержит тексты только по экологической тематике, недостаточно при обучении английскому языку студентов, которые специализируются в экономической географии зарубежных стран и мировом экономическом хозяйстве. По мнению Н.Н. Новицкой, студенты данного факультета имеют более высокий уровень языковой подготовки, чем у остальных, как правило, не ниже языковой спецшколы; многие из них выезжают за границу для участия в научных и молодежных географических конференциях; пишут статьи в зарубежные научные специализированные журналы; поддерживают контакты со своими иностранными коллегами по электронной почте; активно используют Интернет для подготовки курсовых работ и докладов по специальности и т.д. Иными словами, для этих студентов иностранный язык явля- 
ется средством осмысления избранной области знания, реальным инструментом устной и письменной профессиональной коммуникации [11]. Справедливости ради следует отметить, что количество часов, выделенных в учебном плане на занятия по английскому языку для студентов географического факультета МГУ имени М.В. Ломоносова, тоже значительно больше, чем для студентов «общего потока».

На основании представленного опыта становится очевидной потребность в создании учебного пособия по иностранному языку, которое отвечает современным требованиям, предъявляемым к знанию иностранного языка специалистами, ориентировано на профессиональные интересы студентов по конкретному профилю, укладывается в прокрустово ложе часов, отведенных в программе на изучение иностранного языка данной специальности. Решение этой задачи ложится на плечи преподавателей кафедры, обслуживающей ту или иную специальность неязыковых факультетов. Не все преподаватели так называемых общевузовских кафедр иностранных языков имеют достаточный опыт профессионально-ориентированного обучения, как уже отмечалось выше, в основном преподавателям приходится заниматься самосовершенствованием, в том числе и при создании учебных пособий для специальных целей. Основываясь на опыте коллег и собственном опыте обучения студентов неязыковых факультетов вуза, опыте написания учебно-методических пособий, следует отметить принципы, на основе которых пособия создавались:

- по содержанию учебный материал должен относиться к сфере профессиональных знаний студентов;

- отбор материала осуществляется из аутентичных учебников соответствующей специальности/профиля студентов;

- принцип прагматичности предполагает обязательное включение в обучение фрагментов профессионально-делового общения (Business English), типичных для реальной коммуникации;

- учебный материал представляет собой логически последовательное изложение как фундаментальных основ, так и наиболее актуальных проблем данной области науки. Общая тематика учебного материала способствует закреплению у студентов знаний по изучаемой ими специальности;

- принцип профессиональной адекватности означает, что отобранные тексты должны содержать терминосистему будущей профессии, чтобы обеспечить понятийную и концептуальную готовность студентов в процессе непосредственного и опосредованного профессионального общения;

• учет коммуникативно-профессиональных потребностей студентов.

Наличие четкого представления о сущности и содержании межкультурного компонента профессионально-ориентированного обучения требует обращения к факторам, обеспечивающим эффективность учебного процесса. В данном контексте заслуживает внимания позиция Н.Н. Балабас: 
- рациональное использование времени;

- комплексный характер занятий;

- использование аутентичного материала;

- регулярное использование аудио- и видеоматериалов;

- осознанная мотивация изучения иностранного языка с целью практического применения знаний в своей профессиональной деятельности [12].

К сожалению, рамки одной статьи не позволяют рассмотреть модели профессионально-ориентированного обучения иностранному языку, к тому же анализ существующих моделей данного рода позволяет говорить, что в большинстве своем они носят узкопрофильный характер.

Очевидно, что, работая с будущими педагогами-психологами и психологами инклюзивного образования, на занятиях используются материалы по профилю будущей специальности, а значит, и наша модель носит узкопрофильный характер, несмотря на различное сочетание инновационных подходов и технологий обучения. Основной задачей на занятиях по иностранному языку становится создание обстановки реального общения с целью научить языку именно как средству общения. Активному использованию языка в живых, естественных ситуациях помогает многонациональный состав групп. В группе из 13 человек, где основной состав - русскоязычные студенты, 3 студента из Турции и 1 представитель Китая, студенты волей-неволей вынуждены общаться на признанном международном языке - английском как на бытовые, социальные темы, так и на темы, ориентированные на будущую профессию. Используемые на занятиях дискуссии по узкопрофессиональной тематике, реферирование и обсуждение научных статей позволяют осуществлять контакт, развивать способность понимать и передавать информацию. Профессионально-ориентированный подход к обучению иностранным языкам не может обойтись без использования в образовательном процессе таких технических средств, как всемирная сеть - Интернет и её ресурсы (веб-сайты, электронная почта, телекоммуникационные проекты, блоги, видеоконференции, чат-сессии, форумы и др.). Предполагается, что современный преподаватель иностранного языка владеет данным арсеналом технических средств обучения. Нами предпринята попытка общения со сверстниками-носителями языка (студенты различных учебных заведений США) через скайп. Модульная программа занятий предполагает первоначальное знакомство и общение на традиционные темы социально-бытового характера, разговор о традициях и обычаях стран, представителями которых являются студенты, при этом студент должен обладать сведениями страноведческого характера, в том числе знанием реалий, имеющих место в стране изучаемого языка. Следующий модуль представляет собой переход к межкультурной коммуникации профессионально-ориентированной тематики. Сложность заключается не в многоязычии участников и разном уровне языковой компетенции, как могло по- 
казаться на первый взгляд, а в технической стороне вопроса. Большая временная разница между континентами, привязка к одной специализированной аудитории в вузе (практика показала, что индивидуальная работа из дома менее эффективна), ограниченное количество часов, отведенных на дисциплину «Иностранный язык» по учебному плану, не позволяют использовать такой формат занятий регулярно. Различные формы внеаудиторной работы, такие как клубы, участие студентов в международных конференциях, форумах с ориентацией на будущую профессию, способствуют формированию профессиональной компетенции будущих специалистов и развитию способностей межкультурного общения, в том числе на иностранном языке. Огромный потенциал для профессиональноориентированного обучения на неязыковых специальностях несет факультативная форма. На то существует целый ряд объективных причин:

- кардинальные политические и экономические изменения в жизни страны затронули и высшую школу, что повлекло за собой изменение приоритетов языкового образования;

- большая открытость страны и введение рыночной экономики определили перемены в требованиях, предъявляемых к квалифицированному специалисту, его уровню владения языком.

Факультатив позволяет значительно расширить возможности преподавания языка и сделать саму систему обучения языку более гибкой. Студенты получают возможность совершенствовать язык в течение всего периода обучения в вузе, а не только в рамках программы, а также факультатив реально позволяет вводить многоуровневую систему обучения языку. К сожалению, руководители факультетов и администрация вуза не всегда понимают необходимость такого вида внеаудиторной работы и не идут навстречу преподавателям иностранных языков, мотивируя большой загруженностью студентов другими вилами работы. Необходимо искать другие пути, позволяющие осуществлять профессионально-ориентированную подготовку студентов за рамками основной программы. В Челябинском государственном педагогическом университете у студентов неязыковых факультетов есть уникальная возможность овладеть профессиональными иноязычными коммуникативными навыками, обучаясь в Институте дополнительных творческих педагогических профессий (ИДТПП).

\section{Список литературы}

1. Грушевицкая Т.Г., Попков В.Д., Садохин А.П. Основы межкультурной коммуникации: учебник для вузов / под ред. А.П. Садохина. - М.: ЮНИТИ-Дана, 2003.

2. Дмитриева Е.В. К вопросу обучения межкультурной коммуникации [Электронный ресурс]. - URL http:// conference.osu.ru/assets/files/conf_in-fo/cjnf2/6.pdf.

3. Садохин А.П. Межкультурная коммуникация: учеб. пособие. - М.: АльфаМ.; ИНФРА-М, 2004. 
4. Межкультурная коммуникация. Учебные программы /отв. ред. А.В. Павловская. - М., 1997.

5. Постоев В.М. Зависимость методики обучения иностранному языку в неязыковом вузе от специфики факультета // Иностранные языки в высшей школе. - 1974. Вып. 9. - С. 4-13.

6. Образцов П.И., Иванова О.Ю. Профессионально-ориентированное обучение иностранному языку на неязыковых факультетах вузов: учеб. пособие / под ред. П.И. Образцова. - Орел: Изд-во ОГУ, 2005.

7. Рощина Е.В. Функции иностранного языка как учебного предмета в системе обучения в университете // Иностранные языки на неспециальных факультетах: межвуз. сб. - Л.: Изд-во Ленингр. ун-та, 1978. - С. 3-6.

8. Ляховицкий М.В. О некоторых базисных категориях методики обучения иностранным языкам // Иностранные языки в школе. - 1973. - № 1. - С. 27-33.

9. Скрозникова В.А., Боданкина Р.Н. Страноведческий комментарий как одна из форм реализации межпредметных связей // Иностранные языки в высшей школе. 1978. - Вып. 13. - С. 113-116.

10. Апухтина Н.Н. О некоторых вопросах профессионально-ориентированного обучения иностранному языку в технических высших учебных заведениях по горным и геологическим специальностям // Современные тенденции в обучении иностранным языкам и межкультурной коммуникации: материалы междунар. заоч. науч.практ. конф. - Электросталь: Изд-во Нов. гум. ин-та, 2011. - С. 11-14.

11. Современные теории и методики обучения иностранным языкам / под общ. ред. Л.М. Федоровой, Т.И. Рязанцевой. - М.: Экзамен, 2004.

12. Балабас Н.Н. О некоторых особенностях эффективного преподавания профессионально ориентированного иностранного языка (на примере французского языка) // Современные тенденции в обучении иностранным языкам и межкультурной коммуникации: материалы междунар. заоч. науч.-практ. конф. - Электросталь: Издво Нов. гум. ин-та, 2011. - С. 19-21.

\section{References}

1. Grushevitskaia T.G., Popkov V.D., Sadokhin A.P. Osnovy mezhkul'turnoi kommunikatsii [Fundamentals of intercultural communication]. Ed. by A.P. Sadokhin. Moscow: IuNITI-Dana, 2003.

2. Dmitrieva E.V. K voprosu obucheniia mezhkul'turnoi kommunikatsii [On teaching intercultural communication], available at: http:// conference.osu.ru/assets/files/conf_info/cjnf2/6.pdf (accessed 10.02.2016).

3. Sadokhin A.P. Mezhkul'turnaia kommunikatsiia [Intercultural communication]. Moscow: Al'fa-M.; INFRA-M, 2004.

4. Mezhkul'turnaia kommunikatsiia. Uchebnye programmy [Intercultural communication. Curriculum]. Ed. by A.V. Pavlovskaia. - M., 1997.

5. Postoev V.M. Zavisimost' metodiki obucheniia inostrannomu iazyku v neiazykovom vuze ot spetsifiki fakul'teta [Dependence of methodology of teaching foreign language from peculiarities of non-linguistic faculties]. Inostrannye iazyki v vysshei shkole. 1974, no. 9, pp. 4-13. 
6. Obraztsov P.I., Ivanova O.Iu. Professional'no-orientirovannoe obuchenie inostrannomu iazyku na neiazykovykh fakul'tetakh vuzov [Profession-oriented teaching of foreign languages at non-linguistic faculties]. Ed. by P.I. Obraztsova. Orel: Izd-vo OGU, 2005.

7. Roshchina E.V. Funktsii inostrannogo iazyka kak uchebnogo predmeta v sisteme obucheniia $\mathrm{v}$ universitete [Functions of foreign language classes in the system of university education]. Inostrannye iazyki na nespetsial'nykh fakul'tetakh: mezhvuz. sb. Leningrad: Izdvo Leningr. un-ta, 1978, pp. 3-6.

8. Liakhovitskii M.V. O nekotorykh bazisnykh kategoriiakh metodiki obucheniia inostrannym iazykam [On some basic categories of foreign language teaching methodology]. Inostrannye iazyki v shkole, 1973, no. 1, pp. 27-33.

9. Skroznikova V.A., Bodankina R.N. Stranovedcheskii kommentarii kak odna iz form realizatsii mezhpredmetnykh sviazei [Cultural notes as a form of cross-discipline links realization]. Inostrannye iazyki v vysshei shkole, 1978, no. 13. pp. 113-116.

10. Apukhtina N.N. O nekotorykh voprosakh professional'no-orientirovannogo obucheniia inostrannomu iazyku $\mathrm{v}$ tekhnicheskikh vysshikh uchebnykh zavedeniiakh po gornym i geologicheskim spetsial'nostiam [On some issues in profession-oriented teaching of foreign languages in technical universities of geology and mining students]. Sovremennye tendentsii $v$ obucheni inostrannym iazykam $i$ mezhkul'turnoi kommunikatsii: materialy mezhdunar. zaoch. nauch.-prakt. konf. Elektrostal': Izd-vo Nov. gum. in-ta, 2011, pp. 11-14.

11. Sovremennye teorii i metodiki obucheniia inostrannym iazykam [Modern theories and methods of teaching foreign languages]. Ed. by. L.M. Fedorova, T.I. Riazantseva. Moscow: Ekzamen, 2004.

12. Balabas N.N. O nekotorykh osobennostiakh effektivnogo prepodavaniia professional'no orientirovannogo inostrannogo iazyka (na primere frantsuzskogo iazyka) [On some aspects of effective teaching profession-oriented foreign language (French language)]. Sovremennye tendentsii $v$ obucheni inostrannym iazykam $i$ mezhkul'turnoi kommunikatsii: materialy mezhdunar. zaoch. nauch.-prakt. konf. Elektrostal': Izd-vo Nov. gum. in-ta, 2011, pp. 19-21.

\section{Получено 19.02.2016}

\section{Сведения об авторе}

\section{САННИКОВА Светлана Владимировна \\ e-mail: svetlana_chspu@mail.ru}

кандидат педагогических наук, доцент кафедры иностранных языков Челябинского государственного педагогического университета (Челябинск, Россия)

\section{About the author}

\section{Svetlana V. SANNIKOVA}

e-mail: svetlana_chspu@mail.ru

Candidate of Pedagogical Sciences, Associate professor, Department of Foreign Languages, Chelyabinsk State Pedagogical University (Chelyabinsk, Russia) 